ness of different portions of the skin, to find the nature and direction of the errors in localization, and to study the influence of attention upon the localization and interpretation of the simultaneous touch stimulations." An investigation of the interesting problem of attention was also made, with especial reference to the question of how many sensations of touch the mind can attend to or grasp at one time. The effect of practice was also carefully examined. The touch stimuli were applied by means of small cork points attached to adjustable tambours, which were connected with a common air-chamber by means of separate pipes. Pressure brought to bear upon the confined air in the chamber caused the cork tips to touch the skin at various parts of the body synchronously, or practically so. Altogether about 2500 tests were made, perhaps the larger number upon students at the University of Illinois.

The following conclusions are substantiated as a result of these experiments. It was shown: (r) that the skin over the joints is more sensitive than elsewhere, permitting greater accuracy of localization; (2) that touches on the back are more distinctly felt, more clearly remembered, and therefore better localized than touches on the front of the body; (3) that on the left side touches are not so well localized as on the right side; (4) that localizations are more correct when the touches occur at points removed from the median linetouches on the median line being very poorly located; $(5)$ that exposed surfaces localize better than portions usually covered with clothing; (6) that piliferous parts are more sensitive; (7) that errors in localization follow certain fixed rules; (8) that the influence of attention is very marked; (9) that the effect of practice is plainly shown; (ro) that two pressure stimulations are often fused into one single sensation, localized at a point removed from either of those at which the stimulations were received; ( $\mathrm{x}$ ) that there is a strong tendency to perceive dermal sensations of purely subjective origin; (I2) that bilateral asymmetry of function is plainly evident in dermal sensations. These experiments have opened a new and interesting field.

AUthor's Abstract.

\title{
EXPERIMENTAL.
}

An Experimental Study of Some of the Conditions of Mental Activity. John A. Bergström. Am. Jour. Psychology, vi. 247-274. Jan. 1894.

Mr. Bergström's study is excellent reading for those who credit experimental psychologists with an overweening desire 'to make the 
facts agree with their theories,' since the thoroughness of the investigation is no more marked than the modest conservatism of the conclusions. The problem was the discovery of the 'natural rhythm,' if there be one, of mental processes. The method consisted in the accurate timing of definite intellectual operations at different periods, about two hours apart, throughout the day and evening. The results, which are given in tabulated and in graphic form, include experiments on seven subjects of whom five were connected with the psychological department of Clark University: in all cases the daily routine was similar. The tested process, except in the case of one subject, consisted, in the first experiments, in sorting a pack of eighty cards, of eight distinct sorts, into ten piles. The experiments were continued through $17,11,11,10,8$, and 5 days respectively, for different subjects; they certainly show the existence of a 'natural rhythm' of mental activity, but the periodicity is individual, not general. The most constant factor is the depression, shown by all the records except one, from morning to night. In the case of two subjects, Mr. Bergström compares the relative variation of different processes : reading, adding and multiplying numbers, and learning nonsense-syllables. The experiments show very slight changes, at different hours, for the simpler processes, and very striking variations for the more complex. Thus the mean averages of each test are 1.02, $1.55,2.37$, and 7.95 seconds respectively for the operations just named. A comparison of the 6 P.M. records after 'exciting physical exercise' with those taken at 4 P.M. shows, in general, a relative stimulation of the simpler processes but, in most cases, a depression of the more difficult: in the records taken after walking, the difference is seldom observed. An observation of the rapidity of the pulse-rate, in connection with the different records, shows in one case a change from 71.3 to 53 , while there was no change in the rate of the mental processes, so that 'mental activity can evidently not be said to vary with the pulse-rate.'

In the second part of his paper Mr. Bergström tabulates and slightly enlarges the results of his earlier study (Am. Jour. Psych., v. 3), and indicates the evident influence of the interference of associations, as shown in the averages of Ebbinghaus, for his eight memory-series, $105,140,142,146,146,148,144,140$ seconds. 'The great increase of the second above the first and the slight difference afterwards ' accords exactly with Mr. Bergström's results, and is explained through the facts that the first series is always best learned, and that the effect of practice later counterbalances that of interference. In conclusion Mr. Bergström considers cases of 'surprising retardation' in thought, such as persisting errors, and emphasizes the prominence of interference as 
an influence which hinders mental processes, and the significance of the inevitable decrease of interference as a negative explanation of the reassertion of the mental energy. The theory is not put forth as a complete one, but it is certainly far more credible than the usual hypotheses which attribute the recovery of the correct associations 'to unconscious cerebration, to summation of stimuli, or to rest.'

Mary Whiton Calkins.

Wellesley College.

\section{MEMORY, IMAGINATION.}

1. La Mémoire des Joueurs d'Échecs qui jouent sans voir. A. BINET.

2. La Psychologie des Auteurs Dramatiques. A. Binet et Jacques Passx. Revue Philosophique, Feb. I894, 222-240.

I. M. Binet, in announcing a forthcoming work on cases of extraordinary memory, reports as a specimen and as typical of the class to which they belong, the experiences of Dr. Tarrasch. T. plays from six to eight games at a time without sight of the board, and he here tells how he does it. His main reliance is on a very vivid imagination of the board and of the arrangement of the men. The board, which is persistently present during the play, is visualized in a small diagram of about $8 \mathrm{~cm}$ square, with the squares light and dark; the men are visualized with something of color and form, but with no regard whatever to material. Next in importance is the power to recall the progress of the game, and here the memory is greatly aided in the case of a good game by the logical order of events. A third factor is the memory of words, e.g. of the judgments interiorly formulated at different points concerning the character of the play. The main thing in playing several games at once is to keep the games distinct. When the opponent's move for a particular game is first announced, it is often found necessary to recall deliberately how that game opened and to trace its history in detail to the point where the stated move becomes significant; but as the games develop they get more clearly differentiated and such detailed reproduction becomes unnecessary. T. seems to have a good but nowise remarkable general memory; in mental arithmetic he reports himself as distinctly deficient.

2. The second article, designated as a study of the conditions of creative imagination, deals principally with the experiences of a comparatively new author, M. de Curel. M. de Curel's method is to invent a situation suggesting a problem, and then to proceed at once to composition. The problem is not worked out logically, but the play grows by a sort of 'crystallization': the original situation becomes very 